\title{
NEW BLACK-FILLED EPOXY COATINGS FOR REPAIRING SURFACE OF EQUIPMENT OF MARINE SHIPS
}

\author{
Andriy BUKETOV ${ }^{1}$, Serhiy SMETANKIN ${ }^{1}$, Pavlo MARUSCHAK ${ }^{* \star}$, Kyrylo YURENIN $^{1}$, \\ Oleksandr SAPRONOV ${ }^{1}$, Viktor MATVYEYEV ${ }^{1}$, Abdellah MENOU ${ }^{3}$ \\ ${ }^{1}$ Dept of Transport Technologies, Kherson State Maritime Academy, Ukraine \\ ${ }^{2}$ Dept of Industrial Automation, Ternopil Ivan Puluj National Technical University, Ukraine \\ ${ }^{3}$ Moroccan Airports Authority, Mohammed V International Airport, Nouaceur, Casablanca, Morocco
}

Received 26 March 2020; revised 20 June 2020, 5 August 2020; accepted 9 August 2020

\begin{abstract}
The methods for ensuring long-term and safe operation of marine equipment due to comprehensive repair technologies that use epoxy oligomers and new compositions based on them are developed. The influence of temperature and UltraSonic Treatment (UST) on the rheological properties of the pure epoxy matrix and compositions based on it is explored. The compositions have different content of nanodispersed soot carbon black of brand PowCarbon 2419G (particle size of $24 \pm 2 \mathrm{~nm})$. It is established that when nanoparticle soot $(q=0.10 \ldots 15.00 \mathrm{pts} \mathrm{wt})$ is introduced into the composition of the epoxy matrix treated with ultrasound, the viscosity of the composition increases gradually. Based on the results obtained, temperature ranges are recommended, in which the viscosity of the studied compositions reaches optimal technological parameters for the effective impregnation of threads, tows and various fabrics, and which provide for the effective application of the composition to the working surfaces of marine equipment. Technical recommendations are given for applying the developed black-filled epoxy compositions to the working surfaces of parts, ship mechanisms and pipeline systems of marine vessels.
\end{abstract}

Keywords: protective coating, application and inspection, nanodispersed soot, rheological behaviour, marine equipment.

\section{Introduction}

The globalization of international trade, in particular, the free movement of goods is impossible without sea transport with an enhanced operational reliability (Emi et al. 1993; Hellio, Yebra 2009). It is known that the technical operation of marine vessels involves a number of technological processes (Soares et al. 2009; Abbas, Shafiee 2020; Gudze, Melchers 2008), such as technical use (ensuring the vessel operation), maintenance (maintaining the vessel in proper (working) condition), repair (restoration of good technical condition). Each of these technological processes ensures the reliable operation of the vessel and requires development and improvement (Yamamoto, Ikegami 1998).

Unfortunately, the existing methods of non-destructive testing of the marine equipment do not allow for a full control over the defect and damage accumulation process. In particular, this applies to the early stage, when the identification and elimination of defects allows restoring the full efficiency of the mechanism (Emi et al. 1993; Davies 2016; Najafi et al. 2019).

At present, Polymer-Composite Materials (PCMs) are used for the repair and maintenance of marine equipment (Najafi et al. 2019; Selim et al. 2017). They allow enhancing the durability of marine equipment and protecting the working surfaces of marine equipment exposed to such environmental factors as sea water, precipitation, solar radiation, and a variety of mechanical loads during storms. From the technological point of view, its main advantages over other anticorrosive coatings include the hardening speed, high adhesion and resistance to chemical and mechanical influences. Polymer composites are easy to apply, which allows you to quickly create an even, monolithic coating (Mardare, Benea 2017).

One of the promising PCMs that quickly and efficiently protect the surfaces of marine equipment from aggressive effects are the materials based on epoxy resins

\footnotetext{
${ }^{*}$ Corresponding author. E-mail: maruschak.tu.edu@gmail.com

\#Editor of the TRANSPORT - the manuscript was handled by one of the Associate Editors, who made all decisions related to the manuscript (including the choice of referees and the ultimate decision on the revision and publishing).
} 
characterized by the enhanced mechanical, adhesive and thermophysical properties, as well as low shrinkage during curing. Examples for coating systems are given in the Class Guideline DNVGL-CG-0288 (DNV GL 2017) and may be modified as regards coating thickness and number of coats, if relevant. The coating shall be epoxy or equivalent, rendering adequate corrosion protection to the surfaces in question, considering the cargo type and mode of operation of the ship (Summerscales 2014).

It is known that chemical or physical-chemical methods are the most effective ones for improving the properties of epoxy binders and PCMs (Davies 2016; Najafi et al. 2019). The properties of epoxy composites are also modified by nanoparticles of various nature (Rubino et al. 2020; Mardare et al. 2016; Buketov et al. 2018; Sapronov et al. 2019). In this case, one of the most important conditions for the successful nanomodification of polymer composites, in addition to the chemically active surface of the particles, is their uniform distribution in the volume of materials, which largely depends on the viscosity of the polymer binder (Khalina et al. 2019). The core competency of the resulting coating is that even though no abrasion resistance, strength or robustness of the coating is lost, the particles can reversibly act as energy storage units, absorbing the acute pressure of abrasive loads. The particles are permanently bound to the resin binder polymers, due to the binding moieties (Fu et al. 2019). They act like nanosprings in the coating. Their existence does not modify the ability of the epoxy coating to adhere on the substrate. The polymer planes and "inclusions" remain resistant to impact or abrasion (Arabatzis et al. 2019), however, much of the damaging energy is absorbed before the coating cracks, flakes or fails (Maruschak et al. 2012a).

A common drawback of epoxy binders is a fairly rigid molecular structure that leads to an increase in viscosity, which complicates the application of coatings to the surface of the equipment. To solve this problem, various diluents are used in the form of solvents and plasticizers, which are introduced into the polymer matrix in a wide range of concentrations (Il'ina et al. 2019). A negative effect of such operation is the impairment of physicalmechanical properties and significant shrinkage of PCM associated with loosening of the structure of the polymer binder (Brusentseva et al. 2015; Buketov et al. 2019; Geng et al. 2016). The Glass Transition Temperature (GTT) and the strength of the PCM obtained are also lowered. In turn, the use of solvents causes the formation of a large number of pores and the appearance of residual stresses in the volume of the composites. Another method for changing the viscosity of polymer systems is the targeted influence of energy fields during their formation. It is known that UltraSonic Treatment (UST) and heating of polymer mixtures leads to changes in a number of their properties, including viscosity (Ganiev 2007; Sharma, Luzinov 2011; Buketov et al. 2014). UST does not impair the physicalmechanical and thermophysical properties of the compos- ites obtained. Moreover, a decrease in the viscosity of the compositions makes it possible to simplify the technological process of applying coatings to the surface of marine equipment. In this article, a number of approaches to the development of this technique are proposed.

The time, during which the polymer binder retains the ability to bind polymer compositions to solid surfaces (substrates) under the influence of various hardeners, is one of the most important technological properties of thermosetting oligomers. The time interval from the preparation of the polymer binder to the moment it passes into a system of infinite viscosity, i.e., a gel (gel point) is called as gelatinization (Mulder 1996). The optimization of these conditions makes it possible to optimize the coating process and improve its physical and mechanical properties (Buketov et al. 2016).

The purpose of this work was to ensure long-term and safe operation of the marine equipment due to comprehensive repair technologies that use epoxy oligomers and new compositions based on them.

\section{Materials and methods of study}

A correct and timely assessment of the material effectiveness is only possible based on determining the economic efficiency of the technical decisions made. The economic effect is divided into actual (obtained by saving production resources) and conditional (cost reduction in the future). The effectiveness of applying the developed polymer materials based on epoxy resin (ED-20), PolyEthylene PolyAmine (PEPA) is due to the effective protection of marine equipment. The epoxy oligomer ED-20 (GOST 10587-93 and standard ASTM D4762-08) was investigated. The characteristics of the binder are given in Table 1 .

Nanodispersed soot carbon black of brand PowCarbon 2419G - Chemical Abstracts Service (CAS) No 1333-86-4, European Inventory of Existing Chemical Substances (EINECS) No 215-609-9 - manufactured by Black Diamond Material Science Co., Ltd. (China) was used as a filler. The particle size of the powder was determined using electron microscopy and is $24 \pm 2 \mathrm{~nm}$. The characteristics of nanodispersed carbon black are given in Table 2 .

Epoxy PCM was formed using the following technology: preliminary dosing of epoxy resin ED-20, heating the resin to the temperature $T=353 \pm 2 \mathrm{~K}$, and holding at this temperature over the time period $\tau=20 \pm 0.1 \mathrm{~min}$.

Technical Nanodispersed Gas Soot (TNGS) is a hygroscopic material capable of absorbing moisture depending on the particle size (Shaitanov et al. 2013), the presence of impurities and storage conditions. This leads to clumping (sticking) of the TNGS powder and complicates its introduction and dispersion in the polymer medium. In addition, the powder was dried in a muffle furnace heated to the temperature $T=383 \pm 2 \mathrm{~K}$ and held at this temperature over the time period $\tau=60 \pm 0.1 \mathrm{~min}$. Soot was then dosed and introduced into the epoxy oligomer. The filler was introduced in the amount from 0.10 to $25.00 \mathrm{pts} w t$ 
Table 1. Characteristics of nanodispersed soot carbon black of brand PowCarbon 2419G

\begin{tabular}{|c|c|c|}
\hline Characteristic & $\begin{array}{l}\text { Indicator from the } \\
\text { developer company }\end{array}$ & Study method \\
\hline $\begin{array}{l}\text { Mean particle } \\
\text { size }[\mathrm{nm}]\end{array}$ & $24 \pm 2$ & electron microscopy \\
\hline $\begin{array}{l}\text { Specific surface } \\
\text { area }\left[\mathrm{m}^{2} / \mathrm{g}\right]\end{array}$ & $145 \pm 20$ & electron microscopy \\
\hline $\begin{array}{l}\text { Oil absorption } \\
{[\mathrm{cc} / 100 \mathrm{~g}]}\end{array}$ & $85 \pm 5$ & GB/T 7046-2003 \\
\hline $\mathrm{pH}$ & $4.9 \pm 1$ & GB/T 7045-2003 \\
\hline $\begin{array}{l}\text { Staining power } \\
{[\%]}\end{array}$ & $\geq 127$ & GB/T 7050-2003 \\
\hline $\begin{array}{l}\text { Volatile matter } \\
\text { content [\%] }\end{array}$ & $2.3 \pm 0.2$ & GB/T 7047-2006 \\
\hline Density [g/L] & $180 \pm 20$ & GB/T 14853.1-2002 \\
\hline Physical form & powder & without magnification \\
\hline
\end{tabular}

Table 2. Characteristics of epoxy oligomer ED-20

\begin{tabular}{|l|c|}
\hline \multicolumn{1}{|c|}{ Characteristics } & Value \\
\hline Molecular mass $M_{r}$ & 340 \\
\hline $\begin{array}{l}\text { Content of epoxy groups } \\
C_{g}[\%]\end{array}$ & $20.0 \ldots 22.5$ \\
\hline $\begin{array}{l}\text { Content of hydroxyl groups } \\
C_{h}[\%]\end{array}$ & 1.25 \\
\hline Viscosity $\eta[\mathrm{Pa} \cdot \mathrm{s}]$ & $13 \ldots 20$ \\
\hline Density $\rho\left[\mathrm{g} / \mathrm{cm}^{3}\right]$ & 1.160 \\
\hline
\end{tabular}

per 100 pts wt of epoxy oligomer ED-20 (hereinafter, values in parts by weight are given per 100 pts wt of epoxy oligomer ED-20). Then, hydrodynamic combination of TNGS and epoxy oligomer ED-20 particles was applied using UST over the time period $\tau=(1.5 \ldots 2.0) \pm 0.1 \mathrm{~min}$ in similar temperature conditions. After that, the finished compositions were poured into a Griffin glass (according to ISO 7056:1981) in order to conduct further experiments.

The rheological properties of polymer compositions were determined using a BROOKFIELD DV-II+Pro programmable rotational viscometer (Malkin, Isayev 2012) according to GOST 25271-93, as well as according to ISO 2555:89. The principle of operation of the device is based on the rotation of the measuring spindle immersed in the test fluid by means of a calibration coil spring. Each spindle is characterized by two constants, which are used to calculate viscosity, shear stress and shear rate. A standard set of resin viscosity spindles (6 pcs) was used. To obtain the most correct results, the control of the experiment and data collection was carried out automatically using a computer with Brookfield Rheocalc32 software (https:// www.brookfieldengineering.com/products/software/rheocalct) installed. The average dynamic viscosity $\eta$ was determined in the temperature range of $25 \ldots 90{ }^{\circ} \mathrm{C}$ at the same spindle rotation speed, provided that the moment was counted in the range of $10 . . .95 \%$. The thermostating time of the specimens was $15 \pm 0.2 \mathrm{~min}$. The temperature values were displayed using an RTD temperature sensor (from the instrument kit), the error of which is $\pm 1{ }^{\circ} \mathrm{C}$ (the latter can operate in the temperature range of $-100 \ldots+149^{\circ} \mathrm{C}$ ). The temperature in the room at the time of the experiment was $23 \pm 2{ }^{\circ} \mathrm{C}$, and humidity was $64 \pm 2 \%$. The accuracy of viscosity measurements is $\pm 1.0 \%$, and the repeatability of experimental data is $\pm 0.2 \%$.

\section{Research results and their discussion}

At the initial stage, the influence of UST and temperature on the rheological properties of pure epoxy resin, USTmodified resin, and compositions based on it with different concentrations of nanodispersed soot was analysed. When the temperature of epoxy oligomers and compositions based on them with various degrees of filler concentration raised up to $T=310 \mathrm{~K}$, a sharp decrease in the mean dynamic viscosity $\eta$ was found in all the curves, Figure 1. The characteristic kinks on the graphs indicate a change in the phase state of the compositions. With further heating of the test specimens, a monotonic decrease in the mean dynamic viscosity was recorded, which indicates the absence of phase transitions in the temperature range $(T=320 \ldots 360 \mathrm{~K})$.

Changes in dynamic viscosity $\eta$ under the influence of temperature can be traced in greater detail taking into account the data of Table 3. By comparing the properties of epoxy resin ED-20 in the initial state and after the UST according to the above method, it was found that the UST changes the rheological properties of the oligomer. In the range of elevated temperatures $T=321 \ldots 361 \mathrm{~K}$, the dynamic viscosity of the sonicated resin slightly decreased $(\Delta \eta=1.25 \ldots 6.25 \mathrm{mPa} \cdot \mathrm{s})$. At the same time, when the epoxy oligomer is cooled (in the temperature range $T=296 \ldots 316 \mathrm{~K})$, the difference between the viscosity of the sonicated and non-sonicated resin increases: $\Delta \eta=$ 57.5 ...1462.5 mPa.s. In our opinion, the results obtained are associated with high-intensity pulsed hydrodynamic

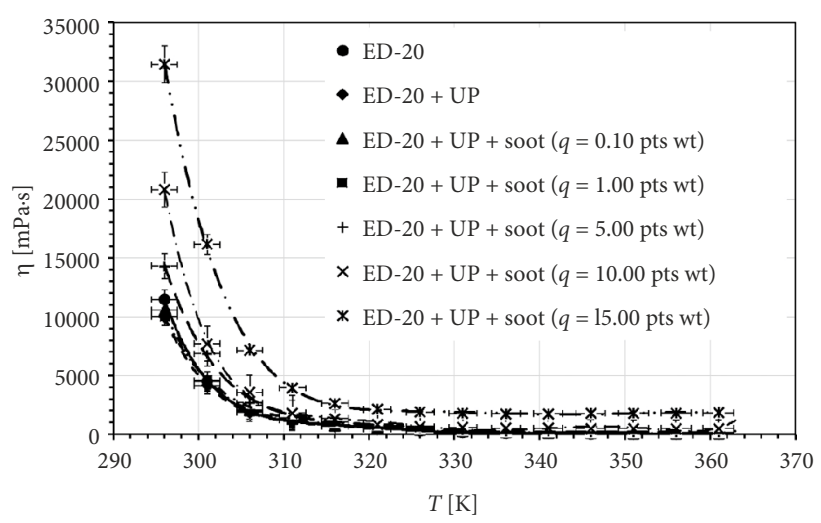

Figure 1 . The effect of temperature $T$ on the mean dynamic viscosity $\eta$ of the sonicated and non-sonicated epoxy resin ED-20 and compositions with nanodispersed soot 
disturbances caused by the collapse of rapidly growing vapour-gas bubbles in the epoxy oligomer volume. Apparently, the shock waves formed upon collapse at the stage of developed cavitation (Brennen 2013) are the main driving factor that leads to the destruction of hydrogen bonds of polymer macromolecules (Sharma, Luzinov 2011; Huang et al. 2002). At the same time, the $\mathrm{C}-\mathrm{C}, \mathrm{C}=\mathrm{C}, \mathrm{C}=\mathrm{O}$ bonds, as well as other types of bonds between individual segments and groups of the main chains of macromolecules, fragment hydrogen bonds while being destroyed themselves. This leads to changes in the physical-chemical properties of the epoxy resin, in particular, a decrease in its viscosity.

Further experiments showed that when the nanodispersed carbon black in the amount $q=0.10 \ldots 15.00$ pts wt is introduced into the sonicated epoxy resin, the viscosity of the compositions increases gradually. It should be noted that the tendency with a phase transition in the region $T=$ $310 \mathrm{~K}$ is also preserved. As is seen from the data displayed in Table 3, the dynamic viscosity of the compositions increases by $9 . . .15 \%$ compared with the oligomer even at minimum concentrations of the introduced filler ( $0.10 \mathrm{pts} \mathrm{wt})$ in the range of elevated temperatures $T=321 \ldots 361 \mathrm{~K}$. In the temperature range that precedes the phase transition $(T=296 \ldots 316 \mathrm{~K})$, an increase in viscosity was $7 \ldots 10 \%$. The experimental results for a composition with the nanodispersed soot content $q=10.00$ pts wt indicate that in the temperature range of $321 \ldots 361 \mathrm{~K}$, the viscosity increases by $92 . . .794 \%$, and in the temperature range of $296 \ldots 316 \mathrm{~K}$, it increases by $52 . .108 \%$. The maximum effect of the filler on the rheological properties of the epoxy compositions was observed after a phase transition at high temperatures. Moreover, the more highly filled the composition, the more pronounced this effect. An increase in the filler concentration enhances the viscosity of epoxy compositions, Figure 1, Table 3, which is possibly associated with an increase in the hydrodynamic and thermodynamic interactions between the oligomer and nanofiller molecules. The agglomeration of nanoparticles in the volume of the epoxy oligomer due to their highly developed surface is also possible, which leads to a limited mobility of macrochains of epoxy resin.

A number of rheological studies made it possible to evaluate the processes that occur during the formation of nanocompositions and to develop technological recommendations for their application on the surface of marine equipment. It is known that in order to obtain a highquality protective layer by the "wet winding" method, and to achieve a good impregnation of threads, bundles and various fabrics, the viscosity of the binder should not exceed 300 ...500 mPa.s (Pahomov et al. 2016). In the paint and varnish industry, there is an empirical rule, according to which the viscosity of about $100 \ldots 500 \mathrm{mPa} \cdot \mathrm{s}$ provides acceptable spraying, brushing or applying of a binder to work surfaces. For the epoxy resin (ED + UST) and the composition (ED + UST + carbon black, $q=0.10$ pts wt), such viscosity values are attained in the temperature range of $321 \ldots 361 \mathrm{~K}$. For the composition (ED + UST + carbon black, $q=1.00 \mathrm{pts} \mathrm{wt})$ - in the temperature range of $326 \ldots 361 \mathrm{~K}$, and for the composition (ED + UST + carbon black, $q=5.00 \mathrm{pts} \mathrm{wt}$ ) - in the temperature range of $331 . .361 \mathrm{~K}$. At the same time, black-filled compositions with nanoparticles content $q=10.00$ pts wt can be used for the "impregnation work" when heated to $361 \mathrm{~K}$. At the same time, compositions with the filler content $q \geq 15.00$ pts wt are unsuitable for such application.

Table 3. Viscosity values of the epoxy composition based on epoxy resin ED-20 at various temperatures and concentrations of the filler

\begin{tabular}{|c|c|c|c|c|c|c|c|}
\hline \multirow{2}{*}{$T[\mathrm{~K}]$} & \multicolumn{9}{|c|}{ Viscosity values $\eta$ [mPa-s] } \\
\cline { 2 - 8 } & ED-20 & ED-20+UST & $\begin{array}{c}\text { ED-20 + UST + } \\
\text { carbon black } \\
(q=0.10 \text { pts wt })\end{array}$ & $\begin{array}{c}\text { ED-20 + UST + } \\
\text { carbon black } \\
(q=1.00 \text { pts wt })\end{array}$ & $\begin{array}{c}\text { ED-20 + UST + } \\
\text { carbon black } \\
(q=5.00 \text { pts wt })\end{array}$ & $\begin{array}{c}\text { ED-20 + UST + } \\
\text { carbon black } \\
(q=10.00 \text { pts wt })\end{array}$ & $\begin{array}{c}\text { ED-20 + UST + } \\
\text { carbon black } \\
(q=15.00 \text { pts wt })\end{array}$ \\
\hline 361 & 56.25 & 56.25 & 61.25 & 68.75 & 173.75 & 503.00 & 1825.0 \\
\hline 356 & 63.75 & 62.50 & 70.00 & 78.75 & 178.75 & 508.00 & 1820.0 \\
\hline 351 & 75.00 & 72.50 & 82.50 & 93.75 & 188.75 & 510.00 & 1800.0 \\
\hline 346 & 90.00 & 87.50 & 100.00 & 113.75 & 206.25 & 511.25 & 1780.0 \\
\hline 341 & 113.75 & 110.00 & 126.25 & 143.75 & 232.50 & 515.00 & 1760.0 \\
\hline 336 & 145.00 & 146.25 & 166.25 & 188.75 & 271.25 & 533.75 & 1760.0 \\
\hline 331 & 202.50 & 196.25 & 228.75 & 257.50 & 337.50 & 583.75 & 1780.0 \\
\hline 326 & 295.00 & 291.25 & 335.00 & 373.75 & 557.50 & 673.75 & 1880.0 \\
\hline 321 & 451.25 & 446.25 & 513.75 & 566.25 & 826.25 & 855.0 & 2125.0 \\
\hline 316 & 722.50 & 665.00 & 710.00 & 745.00 & 1070.0 & 1340.0 & 2645.0 \\
\hline 311 & 1292.50 & 1197.5 & 1292.5 & 1392.5 & 1825.0 & 1820.0 & 3945.0 \\
\hline 306 & 1945.00 & 1860.0 & 2050.0 & 2465.0 & 2700.0 & 3555.0 & 7125.0 \\
\hline 301 & 4515.00 & 4145.0 & 4565.0 & 4590.0 & 6850.0 & 7700.0 & 16150.0 \\
\hline 296 & 11462.5 & 10000.0 & 10000.0 & 10550.0 & 14300.0 & 20800.0 & 31450.0 \\
\hline
\end{tabular}




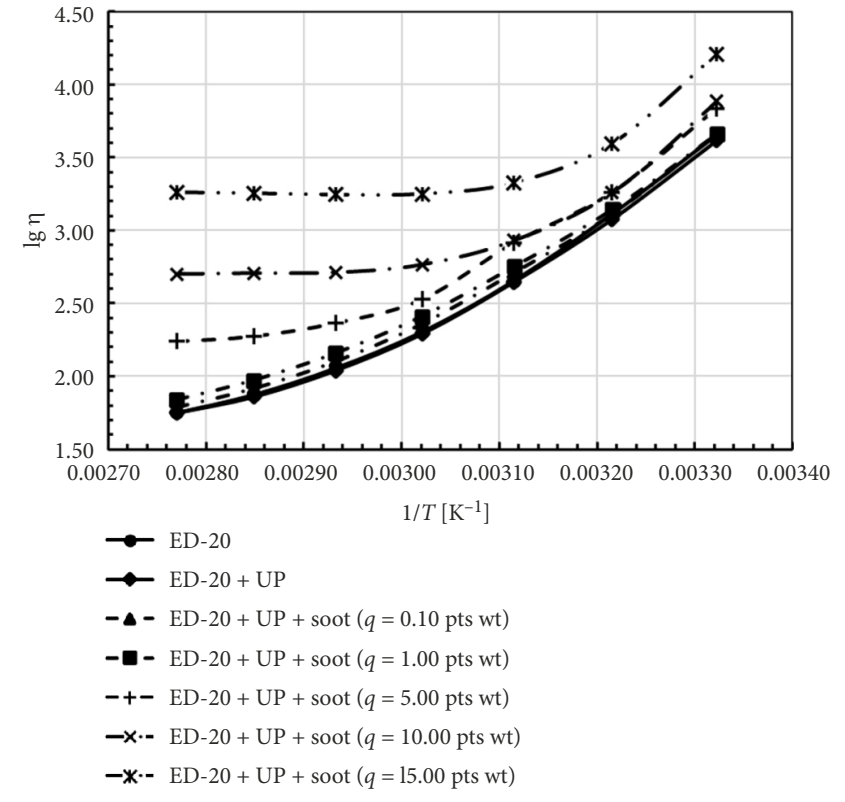

Figure 2. Dependence of viscosity of the sonicated and non-sonicated epoxy resin ED-20 and compositions with nanodispersed soot on the test temperature

The curves showing the influence of test temperature on the viscosity of PCM in the coordinates $(\lg \eta-1 / \mathrm{T})$ are analysed, Figure 2. In this case, the activation energy of the viscous flow was determined for each temperature range separately, i.e., we can talk about the "apparent" or "instantaneous" activation energy of a viscous flow (Shaitanov et al. 2013).

The activation energy is known to be influenced by the chain microstructure and its side branches, which determines the flexibility and interaction between the molecules of polymer compositions in the so-called transition state, in which the destruction and creation of bonds are balanced (Anpilogova et al. 2016; Ermahanova, Ismailov 2018). A decrease in the activation energy indicates the transformation of the initial bonds in epoxy compositions and the formation of new ones, which is also actively promoted by the introduction of nanoadditives. The apparent activation energy $\Delta E_{p}[\mathrm{~kJ} / \mathrm{mol}]$ of the viscous flow was determined by the formula:

$$
\Delta E_{p}=\frac{R \cdot 2.303 \cdot \ln \left(\frac{\eta_{1}}{\eta_{2}}\right) \cdot\left(T_{1} \cdot T_{2}\right)}{T_{2}-T_{1}},
$$

where: $R$ is the universal gas constant, $R=8.314 \mathrm{~J} /(\mathrm{mol} \cdot \mathrm{K})$; $\eta_{1}, \eta_{2}$ are the experimental values of dynamic viscosity [Pa.s]; $T_{1}, T_{2}$ are the temperature values, at which viscosity is determined at a constant shear rate $[\mathrm{K}]$.

The calculation results indicate that the rheological behaviour of PCM is determined not only by the modification of the oligomer, but also by temperature and the amount of the filler introduced, Table 4.

As is seen from Table 4, the lowest activation energy of the viscous flow is in the upper temperature range, which indicates an active formation of a new composition structure (the interaction between macromolecules, segments, side groups of the oligomer and additives wetted during the introduction of nanoparticles into the composition). Further analysis of the data obtained suggests that a decrease in temperature leads to a natural increase in $\Delta E_{p}$, especially for black-filled compositions. This, in turn, indicates that agglomerates of carbon black nanoparticles and macrochains formed in heterogeneous centers of epoxy compositions have a structure that is more resistant to thermosfluctuation decay. The destruction and restoration of such structures requires more thermal energy.

Another important step in optimizing the technology of applying PCM to the surface of marine equipment is the stage of curing. It is known that after mixing with the hardener, this process goes through three stages, i.e., the formation of a liquid, gel and solid phases (Hou et al. 2013) (Figure 3). The first and second stages of PCM polymerization are most important for the formation of high-quality coatings. They determine the time frame for the transition from liquid to gel - gelatinization (working time). Within this period of time, the material retains optimal rheological properties for the effective completion of all technological operations of its formation. At the end of the second and especially the third stage of PCM curing, the viscosity of the compositions increases significantly. They become less fluid, which in most cases makes them unsuitable for further application and repair (Figure 4).

Table 4. Values of the apparent activation energy of the viscous flow of compositions based on ED-20 resin at various filler concentrations

\begin{tabular}{|c|c|c|c|c|c|c|c|}
\hline \multirow{2}{*}{$T[\mathrm{~K}]$} & \multicolumn{7}{|c|}{ Apparent activation energy of the viscous flow $\Delta E_{p}[\mathrm{~kJ} / \mathrm{mol}]$} \\
\cline { 2 - 9 } & ED-20 & ED-20 + UST & $\begin{array}{c}\text { ED-20 + UST }+ \\
\text { carbon black } \\
(q=0.10 \text { pts wt })\end{array}$ & $\begin{array}{c}\text { ED-20 + UST }+ \\
\text { carbon black } \\
(q=1.00 \text { pts wt })\end{array}$ & $\begin{array}{c}\text { ED-20 + UST + } \\
\text { carbon black } \\
(q=5.00 \text { pts wt })\end{array}$ & $\begin{array}{c}\text { ED-20 + UST + } \\
\text { carbon black }(q= \\
10.00 \text { pts wt })\end{array}$ & $\begin{array}{c}\text { ED-20 + UST + } \\
\text { carbon black } \\
(q=15.00 \text { pts wt })\end{array}$ \\
\hline $361 \ldots 351$ & 30.30 & 26.73 & 31.37 & 32.66 & 8.72 & 1.46 & 1.45 \\
\hline $351 \ldots 341$ & 41.44 & 41.47 & 42.33 & 42.52 & 20.74 & 0.97 & 2.24 \\
\hline $341 \ldots 331$ & 54.11 & 54.31 & 55.76 & 54.69 & 34.96 & 11.76 & 1.06 \\
\hline $331 \ldots 321$ & 70.76 & 72.55 & 71.45 & 69.59 & 79.07 & 33.70 & 15.64 \\
\hline $321 \ldots 311$ & 87.32 & 81.91 & 76.55 & 74.66 & 65.75 & 62.69 & 51.33 \\
\hline $311 \ldots 301$ & 97.32 & 96.61 & 98.18 & 92.80 & 102.91 & 112.22 & 109.66 \\
\hline
\end{tabular}




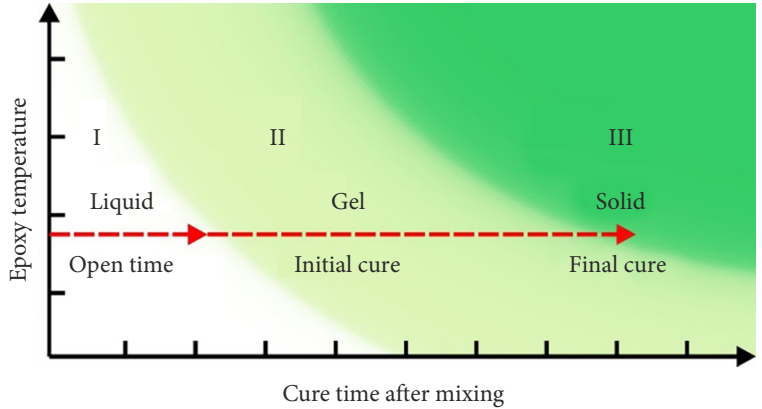

Figure 3. Curing stages of epoxy oligomer (Hou et al. 2013)

a)

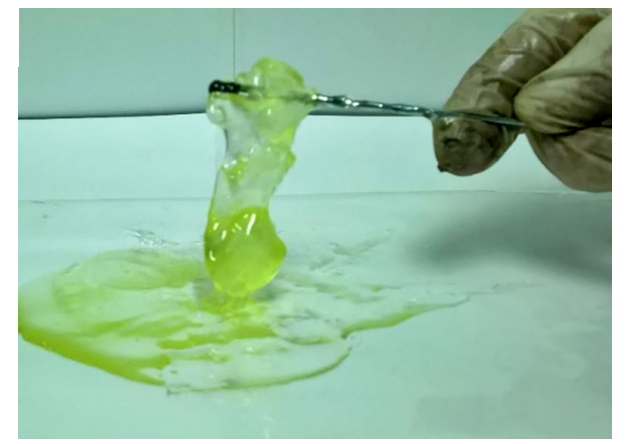

ED-20 (without additives)

b)

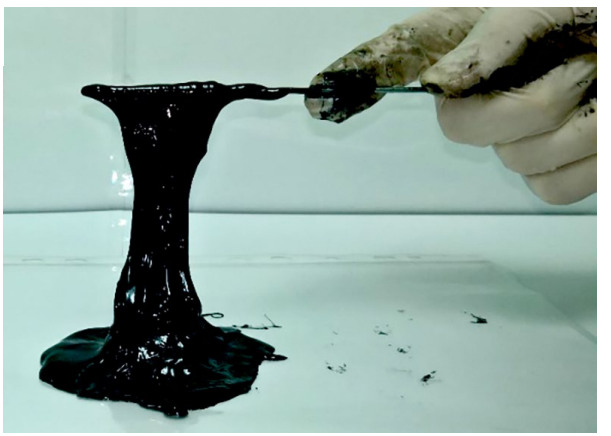

ED-20 + carbon black in the amount of 15.00 pts wt

Figure 4. Images of epoxy oligomer ED-20 with PEPA hardener (a) and epoxy oligomer ED-20 with PEPA hardener and carbon nanosoot (b); viscosity of the consistencies analysed $\geq 47.65 \mathrm{~Pa} \cdot \mathrm{s}$ and 190.2 $\mathrm{Pa} \cdot \mathrm{s}$, respectively

The dependences of the gelation time on the content of nanodispersed soot were determined experimentally. The curing rate of polymer compositions increases significantly with an increase in temperature (in this case, the level of residual stress and shrinkage increases, which affects the physical-mechanical properties of the final product), due to which studies were carried out at a temperature of $23 \pm 2{ }^{\circ} \mathrm{C}$ and an ambient humidity of $64 \pm 2 \%$.

The main patterns of the torque variation in the process of curing of the epoxy resin were established as opposed to the content of nanodispersed soot (Figure 5). When PEPA hardener was introduced into the epoxy oligomer in the amount $q=10.00 \mathrm{pts} w \mathrm{w}$, the torque $T_{t}$ [\%] increased monotonously over $49 \mathrm{~min}$, after which it increased sharply, forming a characteristic kink on the curve. This indicates the beginning of the active formation

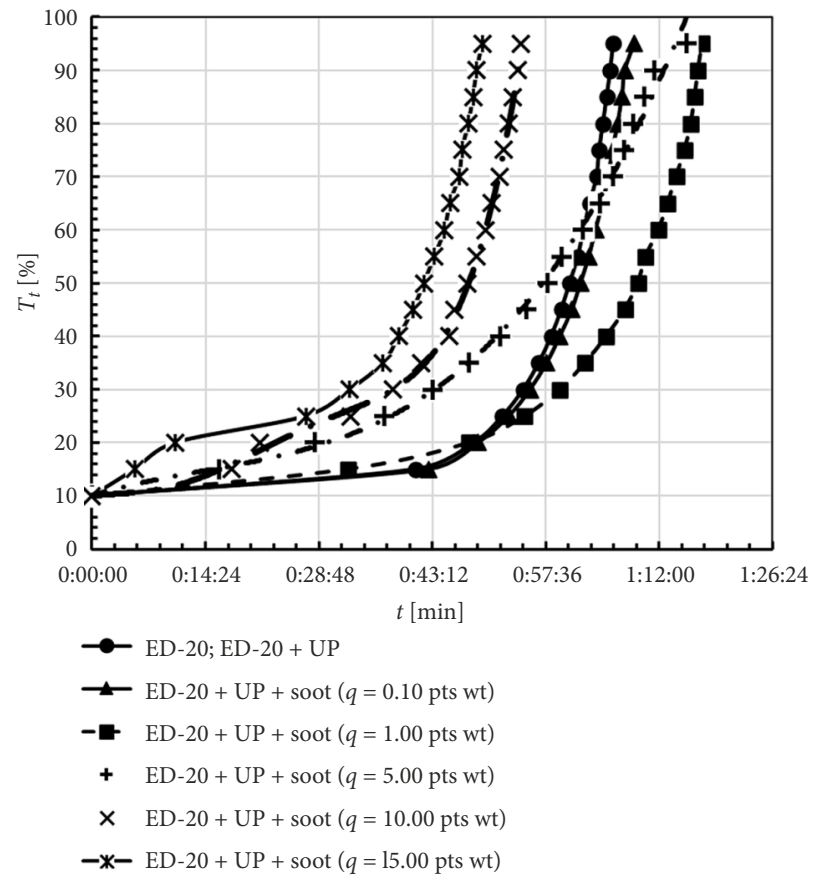

Figure 5. Torque variation in the process of curing of the epoxy resin with different concentrations of nanodispersed soot

of chemical bonds between macromolecular chains and their branches, which facilitates the formation of a threedimensional polymer network with an enhanced density (Sapronov et al. 2020). A similar effect was observed during the curing of epoxy compositions with the content of nanoparticles from 0.10 to $1.00 \mathrm{pts}$ wt.

It should be noted that even a slight increase in the filler content ( $q=0.10$ pts wt) affects the final stage of the PCM gelatinization appreciably. At the same time, an increase in the filler content to $q=1.00$ pts wt leads to a slowdown of the curing process compared to the original ED-20. Further introduction of the filler in the amount $q=5.00 \ldots 15.00 \mathrm{pts}$ wt leads to a significant reduction in gelatinization time and accelerates the curing of PCM. According to the authors, such difference in the kinetics of the polymerization reaction of highly filled nanocomposites primarily indicates a significant interaction between nanoparticles and epoxy resin. An increase in the content of nanoadditives leads, first of all, to an increase in the polymer network density. This causes the appearance of additional friction forces when mixing the consistency, during which energy is released, which transforms into heat, thus accelerating the curing of PCM.

Therefore, we studied the variation of the self-heating temperature of epoxy compositions depending on the intensity of the chemical reaction in the presence of nanodispersed soot with a hardener. The maximum temperature of the exothermic reaction was observed in the composition with the highest content of additive $(q=$ 15.00 pts wt) (Figure 6). At the same time, PCM with the nanodispersed soot content $q=1.00 \ldots 10.00$ pts wt is characterized by a lower exothermic effect, as compared to the materials based on the initial PCM (ED-20) and 


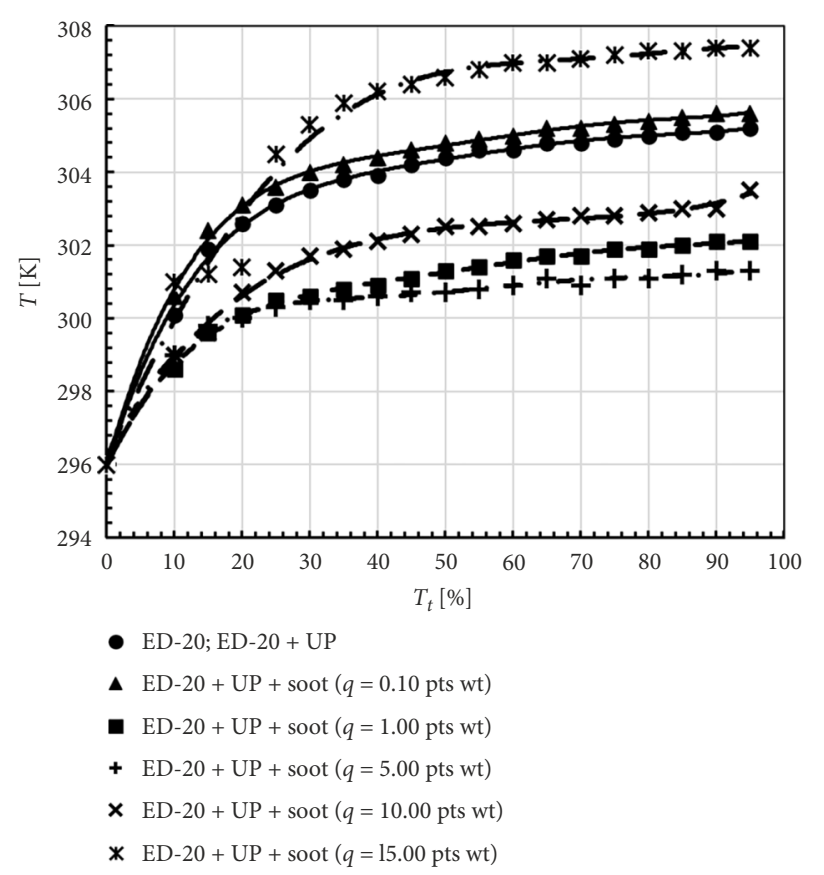

Figure 6. Torque variation relative to the temperature of exoeffect during the curing of epoxy composites with different concentrations of nanodispersed soot

PCM with a minimal content of nanoparticles $(q=0.10$ pts wt). This means that additional dissipation of thermal energy occurs in black-filled composites. Thus, the best properties were obtained for an epoxy oligomer with the gas soot content $q=1.00 \ldots 5.00 \mathrm{pts} \mathrm{wt}$, which is confirmed by the dependence of the survivability time on the beginning of PCM gelatinization, Figure 6. In this case, the lowest exothermic effect among the PCMs tested, which was revealed in the process of curing of the compositions (Figure 6, curves ED-20 + UST + carbon black, $q=1.00 \ldots . .5 .00$ pts wt), should be noted. A more uniform character and low exothermic effect of the curing reaction of the compositions should lead to the formation of a less defective and stressed structure of the PCMs obtained. Obviously, this case is characterized by the most active relaxation processes during the polymerization of compositions.

The above results of investigations into the rheological properties of epoxy composites, as well as features of their curing, are a prerequisite for the development of engineering methods for applying them to the surface of ship mechanisms in order to eliminate defects.

\section{Engineering use of the developed coatings for the repair of ship mechanisms}

Novel surface modification and coating techniques need to be developed in order to successfully translate these coatings toward commercial (large-scale) applications. Every day, coatings with enhanced performances and new properties are being designed and demonstrated, but they never find their way outside the lab (Maan et al. 2020). Combining simple coating techniques with a high cor- rosion durability and crosslinkers or catch-bonds (to enhance mechanical stability), could result in technologically mature coatings with large-scale applicability.

\subsection{Properties of the developed and known protective coatings}

In this section, the authors did not consider the corrosion types and did not make a detailed description of surface preparation methods and surface quality requirements, since these features are described in new recommendations, for example, in ABS (2017) and Vincent (2012), and are relevant both for the existing and new coatings. The basic technological operations for applying coatings have been described. The performance check and troubleshooting of marine equipment were standardized and performed in accordance with RD 31.21.30-97. Technical requirements for cleaning and surface preparation operations were carried out in accordance with ASTM D209303(2017); ASTM D2651-01(2016); BS 7079:2009; ISO 17212:2004.

The developed PCMs were used for the repair of equipment, mechanisms and systems of a marine vessel, such as:

- pipeline systems characterized by corrosion damage (Figures 7,8), due to which the pipe wall becomes thinner and the strength of the system decreases in places of localization of corrosion;

- deck mechanisms (cargo devices) - during storms, critical mechanical stresses arise, which lead to breakdowns of the above-described elements and structures of the vessel.

The use of the developed materials with improved physical and mechanical characteristics (Table 5) will extend time periods between repairs and protect the surface of these systems from corrosion more effectively (Hou et al. 2013; Mouritz et al. 2001; Alam et al. 2013; LópezOrtega et al. 2019).

\subsection{Repair of the hydraulic drive of the control system for closing/opening the lids of holds on SEASPAN LUMAKO 4500 TEU, ME MAN B\&W container ship}

The developed PCMs and methods of their application were tested on the container ship SEASPAN LUMAKO 4500 TEU, ME MAN B\&W with a summer deadweight of 50245 tons (Figure 7) in order to restore the surface and improve the anticorrosion properties of the hydraulic actuator of the control system for closing/opening the lids of holds (Figure 8, position 1). This system is used to seal open spaces, thus ensuring safety of the transported cargo, and is an important element of the ship's unsinkability system, and also makes it possible to quickly provide for transhipment operations. This emphasizes the importance of the above-described element of the ship's hydraulic drive and the need for its high-quality maintenance in a constant working condition. 


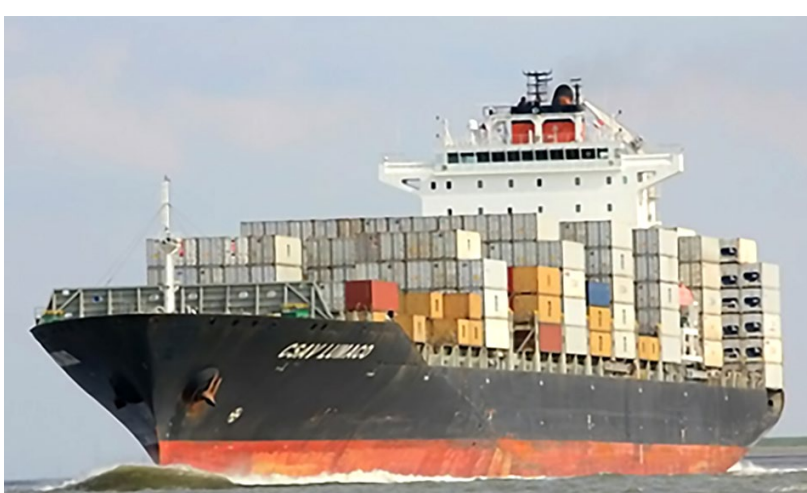

Figure 7. Container ship SEASPAN LUMAKO with the deadweight of 50245 tons (photo by Johnny Verhulst, https://www.marinetraffic.com)

a)

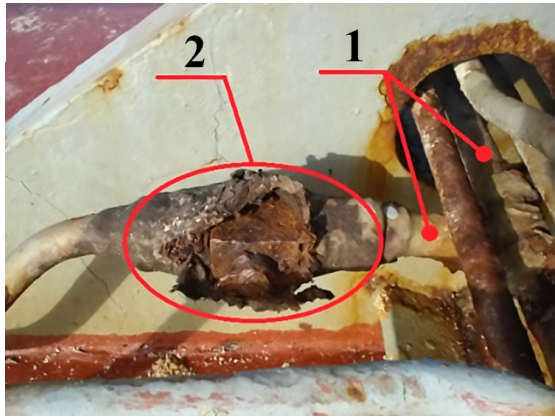

b)

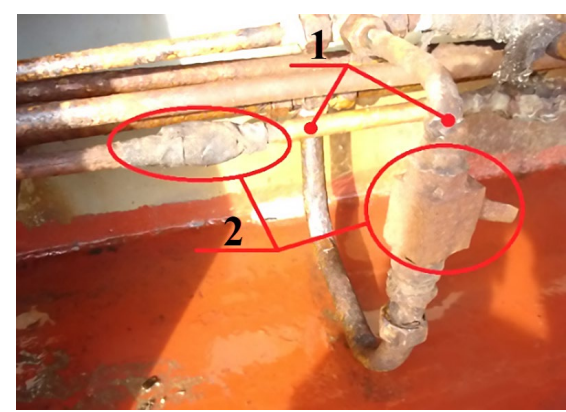

Figure 8. Types of damage hydraulic system for open/ close the cover for cargo holds on a container ship SEASPAN LUMAKO:

1 - damage to the surface of the pipeline hydraulic actuator;

2 - damage to the containment and surface low pressure line
The surface was restored using black-filled epoxy composite coatings (ED + UST + carbon black, $q=1.00 \ldots .5 .00$ pts wt) (Figure 9). To apply the binder to the damaged surface more efficiently and quickly, the mechanized method is used with help of pneumatic spray guns or airless spray guns. To ensure the correct work of the above equipment (the viscosity of the binder should not exceed $500 \mathrm{mPa} \cdot \mathrm{s}$ ), as well as uniform spraying of the PC with a thickness of $0.1 \ldots 0.3 \mathrm{~mm}$, the composite must be preheated to a temperature of $326 \ldots 361 \mathrm{~K}$ and $331 . . .361 \mathrm{~K}$, respectively (Table 3). A PC that consists of fiberglass impregnated with the developed polymer binder was also formed on the surface of the low-pressure valves (Figure 8, position 2) of this system (Figure 9).

\subsection{Repair of the outboard water pipe of the cooling LT contour of container ship MERWE TRADER}

Damage to the outboard water pipe of the cooling (LT) contour was detected. This important line ensures the supply of liquid to the freshwater cooler and further cooling of the ship's power plant. The resulting damage, in our opinion, is due to cyclic loads, temperature changes, mechanical damage during operation, as well as the corrosive effect of the medium (Maruschak et al. 2012b). Repair of permanent type was carried out according to the "wet winding" technique (Figure 10). The coating was applied manually using hair brushes. For a more effective impregnation of reinforcing fibers, the viscosity of the developed compositions did not exceed 300...500 mPa.s. Recommended values for the compositions ED + UST + carbon black, $q=1.00 \ldots 5.00$ pts wt were attained by preheating the binder to a temperature of $331 \ldots 361 \mathrm{~K}$ (Table 3). Similar corrosion damage was detected on the side wall of the flange seat of the freshwater cooler of the LT contour (Figure 11, position 1), which serves to cool auxiliary mechanisms.

The side wall of the freshwater cooler (Figure 11, position 1) was restored by using a composition ED + UST + carbon black $q=1.00 \ldots 5.00$ pts wt. The restoration fol-

Table 5. Comparison of properties of the developed and known Protective Coatings (PC)

\begin{tabular}{|l|c|c|c|c|c|}
\hline \multicolumn{1}{|c|}{ Indicator } & PC 1 & PC 2 & PC 3 & PC 4 & PC 5 \\
\hline Ultimate bending stresses $\sigma_{\text {bend }}[\mathrm{MPa}]$ & $73 \ldots 75$ & 58.6 & $34 \ldots 36$ & $65 \ldots 68$ & $24 \ldots 32$ \\
\hline Modulus of elasticity $E[\mathrm{GPa}]$ & 2.1 & $1.5 \ldots 1.8$ & 2.6 & 2.2 & $1.8 \ldots 2.0$ \\
\hline Impact toughness $W\left[\mathrm{~J} / \mathrm{cm}^{2}\right]$ & $0.9 \ldots 1.0$ & $0.7 \ldots 0.8$ & $0.2 \ldots 0.5$ & $0.4 \ldots 0.9$ & $0.1 \ldots 0.4$ \\
\hline Film thickness $t_{f}[\mu \mathrm{m}]$ & $0.1 \ldots 0.2$ & $0.1 \ldots 0.3$ & $0.1 \ldots 0.2$ & $0.1 \ldots 0.3$ & $0.2 \ldots 0.5$ \\
\hline Total polymerization time $t_{p}[\mathrm{~h}]$ & 72 & $72 \pm 3$ & 168 & 124 & 92 \\
\hline Covering cost $c_{c}[\$ / \mathrm{kg}]$ & 6.1 & 6.3 & 12.4 & 10.2 & 9.6 \\
\hline
\end{tabular}

Notes: PC 1 - the developed nanocomposite coating with the NS content $q=1.00$ pts wt;

PC 2 - the developed nanocomposite coating with the NS content $q=5.00$ pts wt;

PC 3 - a coating developed by Kronocoat Universal (UK);

PC 4 - a coating developed by Marine Service Jaroszewicz s.c. (Poland);

PC 5 - a coating developed by Thordon Bearings Inc. (Canada). 

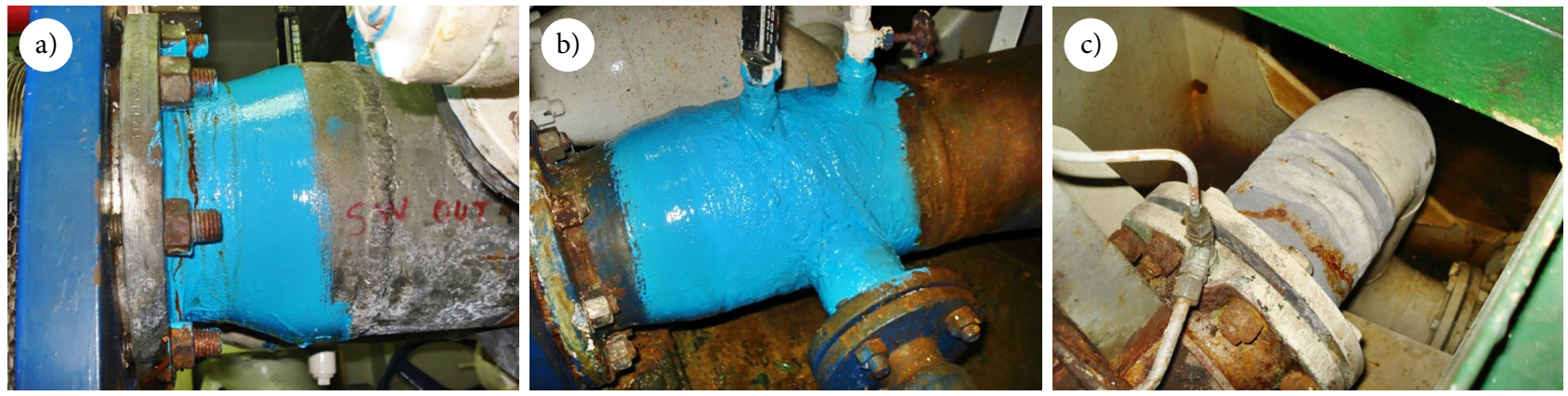

Figure 9. Repair pipe SW (sea water) line for cooling LT (low temperature) contour by comp. materials as Wet Wrap technology of container ship MERWE TRADER (in this case, fiberglass impregnated with compositions based on modified epoxy resins was used)

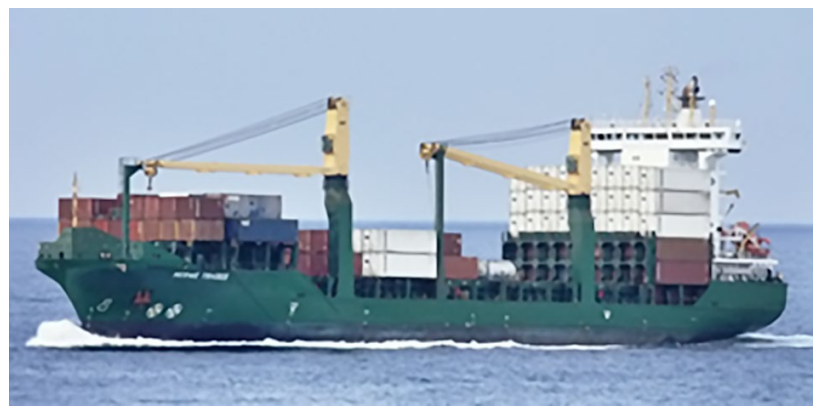

Figure 10. Container ship MERWE TRADER with the summer DeadWeight Tonnage (DWT) of 11842 tons

lowed the preliminary cleaning with a sandblasting apparatus and degreasing of the wall surface, after which a restoring layer of binder was applied to the prepared surface without heating (ASTM D2093-03(2017); ASTM D265101(2016); BS 7079:2009; ISO 17212:2004). This procedure was followed because a composite with a reduced viscosity can drain, forming an uneven layer of PC on the inner surface of the wall.

A variant of restoration and repair is proposed, which is designed for structural elements of the ship crane shown in Figure 12.

Mounting techniques for slewing bearings are shown in Figure 13 A-1 and A-2. Since the PCM is used during installation works (Figure 13, A-2), the connected surfaces fit well enough and are regulated by sliding on a polymer binder, the remains of which are removed from the sides of the connected surfaces. This accounts for significant labour savings during fitting of parts, and also provides for corrosion protection of the internal surfaces of the connected fixtures.

Thus, the basic technological methods for applying the developed PC to marine structures and mechanisms are described. When the binder preparation conditions (heating to the desired viscosity) are observed, it can be applied mechanically using pneumatic spray guns and airless sprayers. This makes it possible to evenly apply the developed coatings of any thickness (including $0.1 \ldots 0.3 \mathrm{~mm}$ ) to significantly larger surfaces, both flat and rough, with corrosive cavities and other types of damage. The recommended temperature-time conditions for heat treatment of the developed composites are shown in Figure 13.

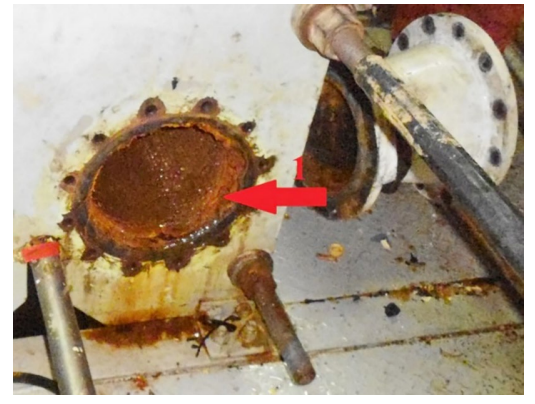

Figure 11. Seat of the flange of the freshwater cooler of the LT contour for cooling auxiliary mechanisms on a container ship MERWE TRADER (position 1 - side wall)

If the heat treatment process is not used, the preliminary polymerization of the adhesive layer is carried out at a temperature $T=293 \ldots 323 \mathrm{~K}$ over a time period $\tau=100 \ldots 120 \mathrm{~min}$, which provides for a high degree of crosslinking of macromolecules with the formation of a spatial grid. For the relaxation of residual stresses and improvement of service characteristics, the total polymerization time is $72 \mathrm{~h}$.

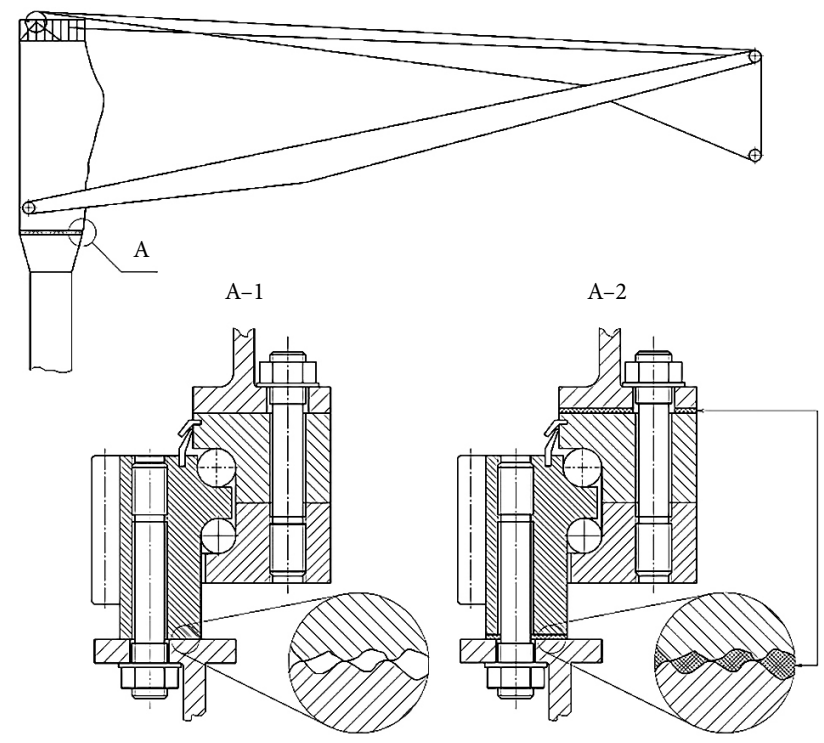

Figure 12. Use of epoxy composites for the maintaining the cargo crane on ship columns - simplified diagram of a slewing crane: A-1 - mounting of a rotary bearing in the traditional way; A-2 - bearing mount using a thin layer of epoxy 


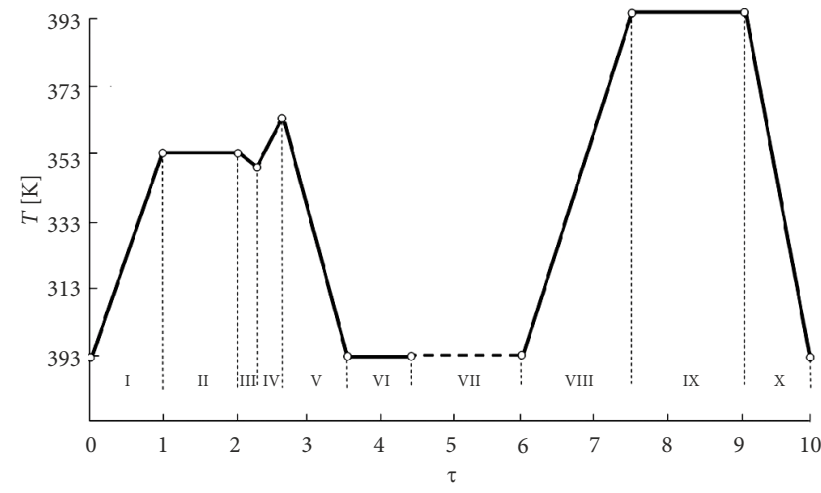

Figure 13. Diagram of temperature-time conditions for the formation of a coating:

I - heating of individual components of the composition, filler and epoxy oligomer ED-20 to a temperature of $353 \pm 2$ $\mathrm{K}(20 \pm 0.1 \mathrm{~min})$;

II - holding epoxy oligomer ED-20 and the filler in the furnace $(20 \pm 0.1 \mathrm{~min})$;

III - hydrodynamic matching of epoxy oligomer ED-20 and the filler $(1 \pm 0.1 \mathrm{~min})$;

IV - thermal treatment of the composition to the specified viscosity values $(20 \pm 0.1 \mathrm{~min})$;

$\mathrm{V}$ - the introduction of the hardener and mixing of the composition $(3 \pm 0.1 \mathrm{~min})$;

VI - applying the composition to a work surface and cooling it to room temperature $(60 \pm 0.1 \mathrm{~min})$;

VII - holding of the composition $(12 \mathrm{~h})$;

VIII - heating the composition to a mixing temperature (35 $\pm 2 \mathrm{~min}$ );

IX - thermal mixing of the composition (120 $\pm 2 \mathrm{~min})$;

$\mathrm{X}$ - cooling of the composition ( $160 \pm 0.5 \mathrm{~min})$.

\section{Conclusions}

Based on experimental studies, new black-filled epoxy coatings for the repair of surfaces of marine equipment are developed, and the conditions for their application are substantiated based on comprehensive studies of their rheological properties.

It is found that the viscosity of the sonicated epoxy matrix is not much lower than that of the initial epoxy oligomer ED-20. In the range of elevated temperatures $(T=321 \ldots 361 \mathrm{~K})$, the dynamic viscosity $\Delta \eta$ of the sonicated resin slightly decreases from 1.25 to $6.25 \mathrm{mPa} \cdot \mathrm{s}$. At the same time, when the epoxy oligomer is cooled, the difference between the sonicated and non-sonicated resin increases significantly and is $\Delta \eta=57.5 \ldots 1462.5 \mathrm{mPa} \cdot \mathrm{s}$ in the temperature range $T=296 \ldots 316 \mathrm{~K}$.

When nanodispersed soot in the amount $q=$ $0.10 \ldots 15.00 \mathrm{pts}$ wt is introduced into the sonicated epoxy resin, the viscosity of the composition increases gradually. It should be noted that with minimum concentrations of the introduced filler $(0.10 \mathrm{pts} w \mathrm{t})$ in the range of elevated temperatures $T=321 \ldots 361 \mathrm{~K}$, the dynamic viscosity of the composition increases significantly (by 9...15\%) compared to the oligomer. At the same time, in the temperature range that precedes the phase transition $(T=$ $296 \ldots 316 \mathrm{~K})$, an increase in viscosity was $7 \ldots 10 \%$. The ex- perimental results obtained for the composition with the nanodispersed soot content $q=10.00 \mathrm{pts}$ wt demonstrate that in the temperature range of $321 \ldots 361 \mathrm{~K}$, the viscosity increases from 92 to $794 \%$, and in the temperature range of $296 \ldots 316 \mathrm{~K}$, an increase is $52 \ldots 108 \%$. Based on the data obtained, we can state that the rheological properties of epoxy compositions are influenced by the filler to a greater extent after a phase transition at high temperatures.

Temperature ranges are recommended, in which the viscosity of the studied compositions reaches the acceptable technological parameters for the effective impregnation of threads, tows and fabrics, as well as for applying the compositions to the working surfaces of objects under repair. For the epoxy resin (ED + UST) and the composition (ED + UST + carbon black, $q=0.10$ pts wt), such viscosity values are attained at a temperature of $321 \ldots 361 \mathrm{~K}$, for the composition (ED + UST + carbon black, $q=$ $1.00 \mathrm{pts} \mathrm{wt}$ ) - at a temperature range of $326 \ldots 61 \mathrm{~K}$, and for the composition (ED + UST + carbon black, $q=5.00$ pts wt) - at a temperature range of $331 . .361 \mathrm{~K}$. Black-filled compositions ( $q=10.00$ pts wt) can be used for the "impregnation works" when heated to $361 \mathrm{~K}$. At the same time, compositions with a higher filler content ( $q=15.00$ pts wt or more) are not suitable for the abovementioned works.

The dependences of the gelation time on the content of nanodispersed carbon black in the developed PCMs are established. The most pronounced effect on the composition curing was obtained with the filler content $q=$ $1.00 \ldots 5.00 \mathrm{pts} \mathrm{wt}$, which provides for a more uniform character of the time dependence on the gelation process. In particular, at a temperature of $23 \pm 2^{\circ} \mathrm{C}$ and an ambient humidity of $64 \pm 2 \%$, the survivability time for compositions with the nanodispersed soot content $q=1.00$ pts wt is $47 \pm 1 \mathrm{~min}$, and when the content of nanoadditives is $q=$ 5.00 pts wt, survivability decreases to $29 \pm 1 \mathrm{~min}$.

Variation of the self-heating temperature of the epoxy binder depending on the intensity of chemical reactions in the volume of the studied compositions was studied. In the process of curing, the smallest exothermic effect was observed in the compositions with the additive content $q=1.00$ pts wt $(T=296 \ldots 302.1 \mathrm{~K})$ and 5.00 pts wt $(T=$ $296 \ldots 301.3 \mathrm{~K}$ ), respectively. This suggests that the minimum exothermic effect and a more uniform nature of the curing reaction should lead to the formation of a less defective and stressed structure of the obtained material. In this case, relaxation processes occur with maximum speed during the polymerization of compositions.

The results obtained made it possible to test the coating technique on a number of marine mechanisms, which made it possible to carry out in-line repairs and restore the performance of marine equipment.

\section{References}

Abbas, M.; Shafiee, M. 2020. An overview of maintenance management strategies for corroded steel structures in extreme marine environments, Marine Structures 71: 102718.

https://doi.org/10.1016/j.marstruc.2020.102718 
ABS. 2017. Guidance Notes on the Application and Inspection of Marine Coating Systems. American Bureau of Shipping (ABS), Houston, TX, US. 122 p.

Alam, M. A.; Sherif, E.-S. M.; Al-Zahrani, S. M. 2013. Fabrication of various epoxy coatings for offshore applications and evaluating their mechanical properties and corrosion behavior, International Journal of Electrochemical Science 8: 3121-3131.

Anpilogova, V. S.; Kravchenko, T. P.; Nikolaeva, N. Ju.; Nej, Zo. L.; Osipchik, V. S. 2016. Reologicheskie svojstva kompozicionnyh materialov na osnove polijetilena vysokoj plotnosti, Plasticheskie massy (5-6): 9-11. (in Russian).

Arabatzis, I.; Skordas, I.; Skordas, D.; Nikolopoulos, L.; Kousiounelos, P.; Boulougouris, E. 2019. Multi-criteria decision-making methodology for the selection of cargo hold coating for bulk carriers, Ships and Offshore Structures 14(6): 609-630. https://doi.org/10.1080/17445302.2018.1534774

ASTM D2093-03(2017). Standard Practice for Preparation of Surfaces of Plastics Prior to Adhesive Bonding.

ASTM D2651-01(2016). Standard Guide for Preparation of Metal Surfaces for Adhesive Bonding.

ASTM D4762-08. Standard Guide for Testing Polymer Matrix Composite Materials.

BS 7079:2009. General Introduction to Standards for Preparation of Steel Substrates before Application of Paints and Related Products.

Brennen, C. E. 2013. Cavitation and Bubble Dynamics. Cambridge University Press. $268 \mathrm{p}$.

Brusentseva, T. A.; Filippov, A. A.; Fomin, V. M.; Smirnov, S. V.; Veretennikova, I. A. 2015. Modification of epoxy resin with silica nanoparticles and process engineering of composites based on them, Mechanics of Composite Materials 51(4): 531-538. https://doi.org/10.1007/s11029-015-9523-6

Buketov, A.; Brailo, M.; Yakushchenko, S.; Sapronova, A. 2018. Development of epoxy-polyester composite with improved thermophysical properties for restoration of details of sea and river transport, Advances in Materials Science and Engineering 2018: 6378782. https://doi.org/10.1155/2018/6378782

Buketov, A.; Maruschak, P.; Sapronov, O.; Zinchenko, D.; Yatsyuk, V.; Panin, S. 2016. Enhancing performance characteristics of equipment of sea and river transport by using epoxy composites, Transport 31(3): 333-342.

https://doi.org/10.3846/16484142.2016.1212267

Buketov, A. V.; Sapronov, O. O.; Brailo, M. V.; Aleksenko, V. L. 2014. Influence of the ultrasonic treatment on the mechanical and thermal properties of epoxy nanocomposites, Materials Science 49(5): 696-702.

https://doi.org/10.1007/s11003-014-9664-0

Buketov, A.; Sapronov, O.; Brailo, M.; Stukhlyak, D.; Yakushchenko, S.; Buketova, N.; Sapronova, A.; Sotsenko, V. 2019. The use of complex additives for the formation of corrosionand wear-resistant epoxy composites, Advances in Materials Science and Engineering 2019: 8183761. https://doi.org/10.1155/2019/8183761

Davies, P. 2016. Environmental degradation of composites for marine structures: new materials and new applications, Philosophical Transactions of the Royal Society A: Mathematical, Physical and Engineering Sciences 374(2071): 20150272. https://doi.org/10.1098/rsta.2015.0272

DNV GL. 2017. Corrosion Protection of Ships. Class Guideline DNVGL-CG-0288. 66 p. Available from Internet: https:// rules.dnvgl.com/docs/pdf/DNVGL/CG/2017-05/DNVGLCG-0288.pdf

Emi, H.; Yuasa, M.; Kumano, A.; Arima, T.; Yamamoto, N.; Umino, M. 1993. A study on life assessment of ships and off- shore structures - 3rd report: corrosion control and condition evaluation for a long life service of the ship, Journal of the Society of Naval Architects of Japan 1993(174): 735-744. (in Japanese). https://doi.org/10.2534/jjasnaoe1968.1993.174_735

Ermahanova, A. M.; Ismailov, M. B. 2018. Vlijanie uglerodnyh nanotrubok na process otverzhdenija i prochnost' jepoksidnoj smoly, Kompleksnoe ispol'zovanie mineral'nogo syr'ja 4: 105-114. (in Russian). https://doi.org/10.31643/2018/6445.36

Fu, Y.; Wang, W.; Zhang, L.; Vinokurov, V.; Stavitskaya, A.; Lvov, Y. 2019. Development of marine antifouling epoxy coating enhanced with clay nanotubes, Materials 12(24): 4195. https://doi.org/10.3390/ma12244195

Ganiev, M. M. 2007. On improvement of strength characteristics in composite polymeric materials by epoxy binders ultrasonic treatment, Russian Aeronautics (Iz VUZ) 50(4): 455-458. https://doi.org/10.3103/s1068799807040204

GB/T 7045-2003. Colour Carbon Black - Determination of $\mathrm{pH}$ Value.

GB/T 7046-2003. Colour Carbon Black - Determination of Dibutyl Phthalate Absorption Number.

GB/T 7047-2003. Colour Black - Determination of Volatile Content.

GB/T 7050-2003. Colour Carbon Black - Determination of Tinting Strength.

GB/T 14853.1-2002. Rubber Compounding Ingredients. Pelletized Carbon Black. Part 1: Determination of Pour Density.

Geng, H. T.; Liu, J. C.; Ren, S. 2016. Effects of diluent on mechanical properties of hollow glass microsphere reinforced epoxy resin composite, Key Engineering Materials 680: 525528. https://doi.org/10.4028/www.scientific.net/kem.680.525

GOST 10587-93. Smoly jepoksidno-dianovye neotverzhdennye. Tehnicheskie uslovija. (in Russian).

GOST 25271-93. Plastmassy. Smoly zhidkie, jemul'sii ili dispersii. Opredelenie kazhushhejsja vjazkosti po Brukfil'du. (in Russian).

Gudze, M. T.; Melchers, R. E. 2008. Operational based corrosion analysis in naval ships, Corrosion Science 50(12): 3296-3307. https://doi.org/10.1016/j.corsci.2008.08.048

Hellio, C.; Yebra, D. 2009. Advances in Marine Antifouling Coatings and Technologies. Woodhead Publishing. 784 p.

Hou, J.; Zhu, G.; Xu, J.; Liu, H. 2013. Anticorrosion performance of epoxy coatings containing small amount of inherently conducting PEDOT/PSS on hull steel in seawater, Journal of Materials Science \& Technology 29(7): 678-684.

https://doi.org/10.1016/j.jmst.2013.03.023

Huang, Y. D.; Liu, L.; Qiu, J. H.; Shao, L. 2002. Influence of ultrasonic treatment on the characteristics of epoxy resin and the interfacial property of its carbon fiber composites, Composites Science and Technology 62(16): 2153-2159. https://doi.org/10.1016/S0266-3538(02)00148-3

Il'ina, M. A.; Mashlyakovskii, L. N.; Drinberg, A. S.; Khomko, E. V.; Garabadzhiu, A. V. 2019. Silicon-containing epoxy composites and their use in marine coatings technology, Russian Journal of Applied Chemistry 92(4): 530-542. https://doi.org/10.1134/S1070427219040098

ISO 7056:1981. Plastics Laboratory Ware - Beakers.

ISO 17212:2004. Structural Adhesives - Guidelines for the Surface Preparation of Metals and Plastics Prior to Adhesive Bonding.

ISO 2555:89. Plastics - Resins in the Liquid State or as Emulsions or Dispersions - Determination of Apparent Viscosity by the Brookfield Test Method.

Khalina, M.; Beheshty, M. H.; Salimi, A. 2019. The effect of reactive diluent on mechanical properties and microstructure of epoxy resins, Polymer Bulletin 76(8): 3905-3927. https://doi.org/10.1007/s00289-018-2577-6 
López-Ortega, A.; Bayón, R.; Arana, J. L. 2019. Evaluation of protective coatings for high-corrosivity category atmospheres in offshore applications, Materials 12(8): 1325.

https://doi.org/10.3390/ma12081325

Maan, A. M. C.; Hofman, A. H.; De Vos, W. M.; Kamperman, M. 2020. Recent developments and practical feasibility of polymer-based antifouling coatings, Advanced Functional Materials 30(32): 2000936. https://doi.org/10.1002/adfm.202000936

Malkin, A. Ya.; Isayev, A. I. 2012. Rheology: Concepts, Methods, and Applications. ChemTec Publishing. 528 p. https://doi.org/10.1016/C2011-0-04626-4

Mardare, L.; Benea, L. 2017. Development of anticorrosive polymer nanocomposite coating for corrosion protection in marine environment, IOP Conference Series: Materials Science and Engineering 209: 012056.

https://doi.org/10.1088/1757-899X/209/1/012056

Mardare, L.; Benea, L.; Dănăilă, E.; Dumitraşcu, V. 2016. Polymeric coatings used against marine corrosion of naval steel EN32, Key Engineering Materials 699: 71-79.

https://doi.org/10.4028/www.scientific.net/kem.699.71

Maruschak, P. O.; Panin, S. V.; Ignatovich, S. R.; Zakiev, I. M.; Konovalenko, I. V.; Lytvynenko, I. V.; Sergeev, V. P. 2012a. Influence of deformation process in material at multiple cracking and fragmentation of nanocoating, Theoretical and Applied Fracture Mechanics 57(1): 43-48. https://doi.org/10.1016/j.tafmec.2011.12.007

Maruschak, P. O.; Sorochak, A. P.; Maruschak, O. V. 2012b. Fractodiagnostics of reasons of degradation and failure of steel water pipes, in Transport Means 2012: Proceedings of the International Conference, 25-26 October 2012, Kaunas, Lithuania, 183-186.

Mouritz, A. P.; Gellert, E.; Burchill, P.; Challis, K. 2001. Review of advanced composite structures for naval ships and submarines, Composite Structures 53(1): 21-42. https://doi.org/10.1016/S0263-8223(00)00175-6

Mulder, M. 1996. Basic Principles of Membrane Technology. Springer. 564 p. https://doi.org/10.1007/978-94-009-1766-8

Najafi, M.; Darvizeh, A.; Ansari, R. 2019. Effect of salt water conditioning on novel fiber metal laminates for marine applications, Proceedings of the Institution of Mechanical Engineers, Part L: Journal of Materials: Design and Applications 233(8): 1542-1554. https://doi.org/10.1177/1464420718767946

Pahomov, K. S.; Antipov, Ju. V.; Simonov-Emel'janov, I. D. 2016. Reologicheskie svojstva vjazkogo jepoksidnogo oligomera, Plasticheskie massy (3-4): 13-14. (in Russian).

RD 31.21.30-97. Pravila tehnicheskoj jekspluatacii sudovyh tehnicheskih sredstv i konstrukcij. (in Russian).

Rubino, F.; Nisticò, A.; Tucci, F.; Carlone, P. 2020. Marine application of fiber reinforced composites: a review, Journal of Marine Science and Engineering 8(1): 26.

https://doi.org/10.3390/jmse8010026

Sapronov, O. O.; Buketov, A. V.; Maruschak, P. O.; Panin, S. V.; Brailo, M. V.; Yakushchenko, S. V.; Sapronova, A. V.; Leshchenko, O. V.; Menou, A. 2019. Research of crack initiation and propagation under loading for providing impact resilience of protective coating, Functional Materials 26(1): 114120. https://doi.org/10.15407/fm26.01.114

Sapronov, O.; Maruschak, P.; Sotsenko, V.; Buketova, N.; De Deus, A. B. D. G.; Sapronova, A.; Prentkovskis, O. 2020. Development and use of new polymer adhesives for the restoration of marine equipment units, Journal of Marine Science and Engineering 8(7): 527.

https://doi.org/10.3390/jmse8070527
Selim, M. S.; Shenashen, M. A.; El-Safty, S. A.; Higazy, S. A.; Selim, M. M.; Isago, H.; Elmarakbi, A. 2017. Recent progress in marine foul-release polymeric nanocomposite coatings, Progress in Materials Science 87: 1-32. https://doi.org/10.1016/j.pmatsci.2017.02.001

Shaitanov, A. G.; Surovikin, Yu. V.; Morozov, A. D.; Rezanov, I. V. 2013. Investigation of conductive nanodisperse carbon by Raman scattering spectroscopy, International Polymer Science and Technology 40(12): 25-29. https://doi.org/10.1177/0307174x1304001206

Sharma, S.; Luzinov, I. 2011. Ultrasonic curing of one-part epoxy system, Journal of Composite Materials 45(21): 2217-2224. https://doi.org/10.1177/0021998311401075

Soares, C. G.; Garbatov, Y.; Zayed, A.; Wang, G. 2009. Influence of environmental factors on corrosion of ship structures in marine atmosphere, Corrosion Science 51(9): 2014-2026. https://doi.org/10.1016/j.corsci.2009.05.028

Summerscales, J. 2014. Durability of composites in the marine environment, Solid Mechanics and Its Applications 208: 1-13. https://doi.org/10.1007/978-94-007-7417-9_1

Vincent, L. D. 2012. The Marine Coatings User's Handbook. NACE International. $403 \mathrm{p}$.

Yamamoto, N.; Ikegami, K. 1998. A study on the degradation of coating and corrosion of ship's hull based on the probabilistic approach, Journal of Offshore Mechanics and Arctic Engineering 120(3): 121-128. https://doi.org/10.1115/1.2829532 